\title{
A utilização de tecnologias digitais no Curso de Licenciatura em Matemática PARFOR/EaD da Universidade Federal de Uberlândia ${ }^{1}$
}

\author{
Elivelton Henrique Gonçalves ${ }^{2}$ \\ Fabiana Fiorezi de Marco $^{3}$
}

\begin{abstract}
RESUMO
Esta pesquisa empreendeu esforços no estudo das Tecnologias Digitais (TDs) na formação de futuros professores de Matemática na modalidade a distância, e foi conduzida pela seguinte questão: como as Tecnologias Digitais são metodologicamente abordadas pelos professores no Curso de Licenciatura em Matemática, na modalidade a distância, da Universidade Federal de Uberlândia? Buscando resposta a esse questionamento, foram propostos os objetivos: analisar como professores organizaram o ensino das suas disciplinas abordando as TDs, e analisar como os licenciandos e tutores avaliaram essa abordagem. Como metodologia, a partir da abordagem da pesquisa qualitativa, realizou-se entrevistas com professores e propôs-se questionários aos licenciandos e tutores. Os resultados evidenciaram a importância da proposição de situações formativas que não apenas apresentem as TDs aos licenciandos, mas, também, que permita-os construir conhecimentos sobre sua integração, enquanto ferramentas de ensino, na sala de aula de Matemática.
\end{abstract}

PALAVRAS-CHAVE: Educação a Distância. Tecnologias Digitais. Formação inicial de professores de Matemática.

\footnotetext{
${ }^{1}$ Este artigo é fruto de uma dissertação de mestrado intitulada A utilização de tecnologias digitais no curso de Licenciatura em Matemática PARFOR/EaD da Universidade Federal de Uberlândia, desenvolvida no Programa de Pós-Graduação em Educação da Universidade Federal de Uberlândia (GONÇALVES, 2018).

${ }^{2}$ Doutorando em Educação pelo Programa de Pós-Graduação em Educação da Universidade Federal de Uberlândia Uberlândia, MG, Brasil. https://orcid.org/0000-0003-2969-9380. eliveltonhg@ @otmail.com.

${ }^{3}$ Pós-doutora em Educação pela Universidade de São Paulo. Docente Associada da Universidade Federal de Uberlândia - Uberlândia, MG, Brasil. https://orcid.org/0000-0002-7126-5626.fabiana.marco@ufu.br.
} 
http://dx.doi.org/10.14393/ER-v27n1a2020-16

The use of digital technologies in the undergraduate course in Mathematics PARFOR/Distance Education at the Federal University of Uberlândia

\begin{abstract}
This research focused its efforts on the study of Digital Technologies (DTs) in the education of future Mathematics teachers by distance modality, and it was guided by the following question: how are Digital Technologies methodologically approached by professors of undergraduate studies in Mathematics by distance modality at the Federal University of Uberlândia? Seeking an answer, the following goals were proposed: to analyze how professors organized the teaching of their subjects addressing DTs, and to examine how undergraduate students and tutors evaluate that approach. By adopting the qualitative research approach as methodology, interviews with professors were carried out, and questionnaires were applied to the undergraduate students and tutors. The results demonstrate the importance of proposition of formative processes which not only introduce DTs to the undergraduate students, but also enable them to build knowledge about their integration as teaching tools in the Mathematics classroom.
\end{abstract}

KEYWORDS: Distance Education. Digital Technologies. Pre-Service Mathematics Teacher Education.

\title{
Introdução
}

As Tecnologias Digitais (TDs) ${ }^{4}$ estão cada vez mais presentes na sociedade contemporânea e influenciado, sobremaneira, a vida de todos, desde a nossa formação, as interações socioculturais até a maneira de adquirirmos novos conhecimentos.

Os avanços das TDs têm influenciado, também, significativamente, o desenvolvimento da educação superior a distância no Brasil. Segundo Rosini

\footnotetext{
${ }^{4}$ Neste estudo, é entendido como TDs os computadores, tablets, smartphones, vídeos, softwares, Internet, enfim, os meios computacionais, os dispositivos informáticos e recursos eletrônicos.
} 
(2014), impulsionada pelo desenvolvimento das novas tecnologias e por propiciar ao aluno uma maior flexibilidade para realizar seus estudos em seu próprio tempo e ritmo (o que não implica na inexistência de prazos) sem a necessidade de deslocamento de sua região, adaptando-se à diferentes realidades, a procura pela Educação a Distância (EaD) no país tem crescido gradualmente. Para Zabel e Almeida (2015), houve, nos últimos anos no país, uma expressiva expansão na oferta de cursos de formação de professores por meio da EaD, a qual encontrou mais força a partir da elaboração de legislações ${ }^{5}$, do uso das TDs como forma de comunicação e interação nos cursos, e da criação do Sistema Universidade Aberta do Brasil (UAB) ${ }^{6}$.

A EaD, segundo Moore e Kearsley (2008, p.1), é uma modalidade de Educação na qual "alunos e professores estão em locais diferentes durante todo ou grande parte do tempo em que aprendem e ensinam", sendo desenvolvida, atualmente, com o apoio de inúmeras TDs e podendo ser mesclada ou não com encontros/aulas presenciais. Cabe salientar, conforme afirmam Faria e Salvadori (2010, p.16), que a modalidade a distância "não se trata de uma forma facilitada de conseguir títulos, muito menos de formação de baixa qualidade. Trata-se de um sistema que atende às necessidades de um público específico e está atingindo cada vez mais segmentos". Nesse público, destacase principalmente aquelas pessoas que necessitam de flexibilidade de horário para estudar e/ou residem distantes dos Centros Universitários.

A atual e crescente expansão das TDs, gradualmente, têm avançado os muros das escolas e chegado também às salas de aulas, em especial por meio do uso dos alunos, levando um novo desafio aos professores: "como incorporálas em sua prática pedagógica de forma significativa e não apenas como uma ferramenta para motivar a sua aula?" (CANTINI et al., 2006, p.877). Neste sentido, surge a necessidade dos professores das diversas áreas estarem preparados para lidarem com esse cenário digital que não é mais tão novo.

\footnotetext{
${ }^{5}$ Em especial, destacamos o artigo 80 da Lei 9.394 de 1996, que oficialmente estabeleceu as bases legais e inaugurou a era normativa dessa modalidade educacional no país, e as suas posteriores regulamentações, sendo a mais recente realizada pelo Decreto 9.057 de 2017.

${ }^{6}$ O Sistema UAB foi criado pelo Governo Federal em 2005 com o intuito de expandir e interiorizar a oferta de cursos de Educação Superior no país via EaD, prioritariamente voltados a formação de professores.
} 
Hoje, grande parte de nossos alunos estão cada vez mais envolvidos com as TDs fora da escola, mantendo um constante acesso à Internet para diversos fins, por exemplo, jogos, músicas e, principalmente, redes sociais. Podemos perceber que o perfil dos estudantes que hoje chegam a escola se alterou, transformado pelas TDs que constantemente se inovam com o surgimento de novos aparatos e recursos: "se antes era apenas e fortemente a televisão, hoje são os computadores - cada vez menores e mais potentes - [...] com acesso à Internet” (LOPES, 2010, p.38). Entretanto, nas escolas, afirma Chassot (2003, p.90, grifos do autor), é comum encontramos "docentes desplugados, ensinando a alunos que surfam na Internet".

Dessa forma, parece-nos que é clara a necessidade dos cursos de graduação em Licenciatura em Matemática (no nosso caso) promoverem formação para a utilização das TDs. Contudo, trata-se de uma formação que possibilite ao futuro professor utilizar as TDs para se fazer Educação, e não apenas uma formação instrumental do tipo noções básicas de informática. Refere-se a uma formação que permita ao futuro professor "ampliar a sua visão de mundo acerca das tecnologias, modificando e, ao mesmo tempo, fortalecendo a sua relação com as mesmas e, conscientemente, optar pela melhor forma de integrá-las à sua prática educativa" (LOPES, 2010, p.42).

E ofertar cursos a distância, pontua Neves (2005), pode se tornar uma excelente estratégia de se construir conhecimentos e, ao mesmo tempo, de se dominar as TDs, por meio do desenvolvimento de competências que podem contribuir com a constituição dos futuros professores. Nesse sentido, defendem Schiller, Lapa e Cerny (2011, p.5), os cursos a distância devem considerar as TDs "ao mesmo tempo, objeto de estudo e ferramenta de ensino".

No que tange a formar professores de Matemática na modalidade a distância, Freitas (2014) afirma que é uma missão possível, porém, complexa, especialmente em um cenário ainda em processo de aprimoramento como o da $\mathrm{EaD}$ e de adaptação por parte das universidades e docentes formadores, sobretudo, a dinamicidade dos espaços virtuais de aprendizagem. Assim, a formação a distância de professores de Matemática demanda uma atenção 
cuidadosa, além da oferta de formação aos colaboradores envolvidos. Na formação de professores de Matemática na EaD, continua Freitas (2014), a busca incessante deve se direcionar no sentido de se encontrar estratégias e dinâmicas que, de fato, envolvam o professor em serviço ou o futuro professor, permitindo que eles encontrem/formem uma identidade profissional.

Ante o exposto, as ações e reflexões deste estudo foram conduzidas pela seguinte questão: como as Tecnologias Digitais são metodologicamente abordadas pelos professores no curso de Licenciatura em Matemática, na modalidade a distância, da Universidade Federal de Uberlândia? Assim, as atenções estiveram voltadas a investigar como as TDs foram abordadas nas disciplinas de modo a permitir a reflexão e possível compreensão delas pelos futuros professores de Matemática. Como objetivos específicos tivemos: analisar como professores organizaram o ensino das disciplinas abordando as TDs, e analisar como os licenciandos e tutores avaliaram essa abordagem.

Esta pesquisa teve como contexto o Curso de Graduação em Licenciatura em Matemática, na modalidade a distância, integrante do Plano Nacional de Formação de Professores da Educação Básica (PARFOR), da Universidade Federal de Uberlândia (UFU). Na pesquisa, adotamos a abordagem da pesquisa qualitativa, e realizamos entrevistas com os professores e propusemos questionários aos licenciandos em Matemática e aos tutores.

A organização deste artigo contemplou: primeiramente, um breve panorama do PARFOR e a caracterização do Curso de Licenciatura em Matemática PARFOR/EaD da UFU; em seguida, o percurso metodológico e as análises das informações construídas pela pesquisa a respeito da abordagem das TDs no respectivo curso; e, por fim, alguns apontamentos finais.

\section{O Plano Nacional de Formação de Professores da Educação Básica}

As ações de formação de professores no Brasil vêm ocupando, gradativamente, lugar de destaque, sobretudo, após a promulgação da Lei de Diretrizes e Bases da Educação Nacional (LDB) e a necessidade crescente de 
melhorias da qualidade da educação. Buscando, entre outros aspectos, assegurar a formação exigida na LDB aos professores que atuavam na Educação Básica, foi instituído pelo Ministério da Educação (MEC) o Decreto $\mathrm{n}^{\mathrm{o}} 6.755^{7}$, de 29 de janeiro de 2009, que estabeleceu a Política Nacional de Formação de Profissionais do Magistério da Educação Básica.

Dentre as recomendações previstas nesse decreto, estava a necessidade de se oferecer formação para aqueles docentes que atuavam em áreas diferentes de sua formação inicial na Educação Básica e a necessidade de se priorizar a formação do docente que não possuía formação em ensino superior.

Dessa forma, ainda em 2009, foi criado, em caráter emergencial, o primeiro PARFOR, resultado de uma "ação conjunta do MEC, de instituições públicas de educação superior e das secretarias de educação dos estados e municípios [...]" (BRASIL, 2009, p.6).

Por meio do PARFOR, o professor, em exercício na rede pública de Educação Básica há pelo menos três anos, poderia obter formação em três situações: i) primeira licenciatura: para professores que ainda não tinham formação superior; ii) segunda licenciatura: para professores formados, mas que atuavam em área diferente daquela em que se formaram; e iii) formação pedagógica: para bacharéis sem licenciatura (BRASIL, 2009). Os cursos eram oferecidos na modalidade presencial ou a distância pelo Sistema UAB.

O MEC criou também um sistema eletrônico denominado Plataforma Freire, com o objetivo de reunir informações, gerenciar e acompanhar a participação dos docentes nos cursos no âmbito do PARFOR em todo o Brasil.

Para concorrer a uma vaga nos cursos ofertados, existiu um processo que o professor precisava atentar-se a partir da Plataforma Freire: i) préinscrição no curso; ii) validação da pré-inscrição pela Secretaria de Educação; e iii) processo de seleção realizado pelas Instituições Públicas de Ensino Superior (IPES) a partir do relatório de validação. Aprovado no processo de

\footnotetext{
${ }^{7}$ O Decreto ${ }^{\circ} 6.755$ foi revogado pelo Decreto ${ }^{\circ}$ 8.752, de 09 de maio de 2016, que dispõe sobre a Política Nacional de Formação dos Profissionais da Educação Básica.
} 
validação, o professor estaria apto a realizar sua inscrição na categoria Plataforma Freire no processo seletivo da IPES ofertante do curso.

Com relação a UFU, a Instituição aderiu ao PARFOR por meio da assinatura do Termo de Adesão em 2009. A participação da UFU no PARFOR consistiu na oferta de cursos de primeira licenciatura e segunda licenciatura. Tratando-se do Curso de Licenciatura em Matemática PARFOR/EaD, o Projeto Pedagógico de Curso (PPC) foi aprovado em setembro de 2010 pelo Conselho de Graduação da Universidade.

\section{O Curso de Licenciatura em Matemática PARFOR/EaD da UFU}

A UFU é uma Instituição Pública de Ensino Superior, federalizada em 1978 e com sede na cidade de Uberlândia, estado de Minas Gerais. A Instituição possui uma sólida trajetória no campo da EaD, empreendendo esforços e acumulando experiências com essa modalidade educacional desde 1997, mantendo-se, a partir de então, envolvida com o movimento da EaD em nosso país. Atualmente, o Centro de Educação a Distância (CEaD/UFU), órgão ligado a reitoria e responsável pelo apoio e operacionalização dos cursos a distância na Universidade, oferece cursos de graduação, especialização, aperfeiçoamento e extensão, em diferentes áreas, vinculados ao Sistema UAB.

A primeira turma do Curso de Graduação em Licenciatura em Matemática a distância da UFU, iniciada em 2013/1 e concluída em 2016/2, foi direcionada ao atendimento à demanda assinalada no PARFOR, sendo ofertado pela Faculdade de Matemática (FAMAT/UFU), em parceria com CEaD/UFU, no âmbito do Sistema UAB. Em 2017/1 houve a reoferta de disciplinas para alunos em dependência.

Essa licenciatura foi destinada a professores que lecionavam Matemática na Educação Básica (Ensino Fundamental II e Ensino Médio), na rede pública, e que ainda não haviam concluído um curso superior.

O Curso possuiu carga horária total de 3.095 horas, com duração de 4 anos, divididos em 8 semestres. No total, 40 disciplinas compunham a grade curricular do Curso e foram desenvolvidas, predominantemente, por meio de 
um Ambiente Virtual de Aprendizagem (AVA). O AVA utilizado foi o Moodle (Ambiente Modular de Aprendizagem Dinâmica Orientada a Objetos), uma plataforma computacional de aprendizagem, acessada pela Internet.

Assim, os estudos a distância foram realizados, principalmente, por meio do acesso ao AVA, onde, a partir das ferramentas disponíveis nessa plataforma, os estudantes encontravam anexados os conteúdos, os materiais e as propostas de estudo das disciplinas; efetuavam a postagem de tarefas; e estabeleciam comunicação com todos os envolvidos.

Eram realizados ainda, durante o Curso, nos polos de apoio presencial, encontros presenciais, nos quais havia a possibilidade de realização de webconferências semanais, apresentações de trabalhos e avaliações escritas.

$\mathrm{O}$ apoio e o acompanhamento dos discentes eram realizados de maneira direta e mais constante pela ação dos tutores, sob a orientação dos professores, que, por sua vez, eram os responsáveis pela organização do ensino das disciplinas, elaborando o material de estudo impresso e audiovisual e as tarefas disponibilizadas no AVA, além de esclarecer dúvidas dos alunos por meio de webconferências e/ou tutores e conduzir as avaliações dos alunos.

A avaliação deveria ser realizada em pelo menos duas modalidades, entre elas: obrigatoriamente a realização de avaliações presenciais, equivalendo, no mínimo, a $60 \%$ do total de pontos; e por meio das ferramentas do AVA, correspondendo, no máximo, a 40\% dos pontos. O discente, para obter aprovação, deveria atingir o aproveitamento de, no mínimo, 60\%.

Salientamos que a tutoria foi realizado pelos tutores presenciais e a distância ${ }^{8}$, que possuíam graduação em Matemática e foram submetidos a processo de seleção. Já os professores, são efetivos da UFU e também atuam nos cursos presenciais. Ainda destacamos que é condição obrigatória, aos professores e aos tutores, para atuação nos cursos a distância ofertados pela UFU, a realização de um curso de formação oferecido pelo CEaD/UFU.

\footnotetext{
${ }^{8} \mathrm{O}$ tutor presencial, é o responsável por orientar e acompanhar, presencialmente, os alunos que porventura vão aos polos de apoio presencial a respeito das disciplinas ofertadas no semestre letivo. Já o tutor a distância, orienta e acompanha os alunos virtualmente, geralmente, via AVA. E, normalmente, cada tutor a distância é responsável por uma ou mais disciplinas ofertadas no semestre letivo.
} 
O corpo discente da primeira turma do Curso foi composto por alunos de três polos de apoio presencial, de três cidades mineiras: Bicas, Buritis e Coromandel. Foram oferecidas, com entrada única, 50 vagas para cada um dos polos citados. Considerando que o Curso atendeu à demanda do PARFOR, a forma de acesso prioritário ocorreu via Plataforma Freire. O ingresso na UFU pelos interessados no Curso ocorreu por meio de um processo seletivo presencial e único para todos os polos realizado em 2012, sendo destinadas vagas para as categorias Plataforma Freire e Demanda Social.

De acordo com os dados publicados no website do referido Processo Seletivo ${ }^{9}$, o total de inscritos foi de 148 candidatos. Contudo, tais candidatos referiam-se, somente, à categoria Demanda Social. Os candidatos foram classificados respeitando-se as maiores notas obtidas e as vagas disponíveis nos polos. No total, 99 candidatos efetuaram sua matrícula e iniciaram o Curso em 2013/1 e, desses, 6 concluíram o Curso em 2016/2 e 8 em 2017/110.

\section{O percurso metodológico}

Com base em nossa questão de investigação e dos objetivos almejados pela pesquisa, nos fundamentamos na abordagem da pesquisa qualitativa, uma vez que essa abordagem, como afirma Minayo (2010), busca respostas a questões específicas, ou seja, os dados oferecerão informações detalhadas sobre um caso muito específico. Já os instrumentos metodológicos que entendemos que melhor dialogaram com nosso objeto de estudo foram: questionário com licenciandos e tutores, e entrevista com professores. A pesquisa foi desenvolvida durante 2016/2 e 2017/1. Antes de iniciarmos o processo de obtenção de informações por meio dos referidos instrumentos, a pesquisa possuiu dois momentos inter-relacionados que nos auxiliaram a evidenciar o contexto de ação deste estudo: a análise do PPC e do AVA.

Em um primeiro momento, realizamos a análise do PPC, mais especificamente, das 40 fichas de disciplinas do Curso de Licenciatura em

\footnotetext{
${ }^{9}$ https://www.ingresso.ufu.br/parfor/2013. Acesso em: 18 ago. 2017.

${ }^{10}$ Não foi alvo desta pesquisa investigar o motivo da evasão dos alunos.
} 
Matemática PARFOR/EaD da UFU. Nosso objetivo, nesse momento, era identificar disciplinas que abordaram conteúdos relacionadas às TDs.

A operacionalização desse momento ocorreu-se a partir de leituras sistemáticas das referidas fichas. Desse modo, identificamos seis disciplinas que proporcionaram aos licenciandos conhecimentos acerca das TDs no ensino de Matemática e as organizamos em dois grupos: Grupo A (GA): aquelas com objetivo de habilitar o licenciando a utilizar as TDs; Grupo B (GB): aquelas que almejaram promover reflexões teóricas sobre o uso das TDs.

Após a análise do PPC, propusemos um questionário aos alunos do curso, como veremos adiante. Nesse questionário, os alunos assinalaram mais outras duas disciplinas que envolveram o uso de alguma TD nas tarefas propostas. Consideramos, também, essas disciplinas, organizando-as em um Grupo C (GC). A classificação em grupos foi apenas a título de organização das informações. A seguir, no Quadro 1, apresentamos as disciplinas.

QUADRO 1: Relação das disciplinas resultantes da Análise do PPC

\begin{tabular}{|c|l|c|c|}
\cline { 2 - 4 } \multicolumn{1}{c|}{} & \multicolumn{1}{|c|}{ Disciplina } & Semestre & Professor $^{\mathbf{1 1}}$ \\
\hline \multirow{4}{*}{ GA } & Introdução à Educação a Distância & $1^{\circ}$ & Daniela \\
\cline { 2 - 4 } & Informática e Ensino de Matemática & $3^{\circ}$ & Fernando \\
\cline { 2 - 4 } & TIC no Ensino de Matemática & $7^{\circ}$ & Lucas \\
\hline \multirow{3}{*}{ GB } & Tendências em Educação Matemática & $5^{\circ}$ & Fernando \\
\cline { 2 - 4 } & Estágio de Prática Pedagógica III & $7^{\circ}$ & Daniela \\
\cline { 2 - 4 } & Estágio de Prática Pedagógica IV & $8^{\circ}$ & Daniela \\
\hline \multirow{2}{*}{ GC } & Geometria Plana e Desenho Geométrico & $2^{\text {o }}$ & Eduardo \\
\cline { 2 - 4 } & Modelagem Matemática & $5^{\text {o }}$ & Bruna \\
\hline
\end{tabular}

Fonte: Elaborado pelos autores.

Portanto, averiguamos que no referido Curso haviam, dentre suas 40 disciplinas, 8 que abordaram as TDs e/ou que desenvolveram alguma proposta envolvendo-as. Isto é, essas oito disciplinas tiveram as TDs como objeto de estudo e não apenas utilizaram o AVA para disponibilizar conteúdos ou tarefas.

\footnotetext{
${ }^{11}$ Com o intuito de preservar a identidade dos participantes desta pesquisa, todos os nomes utilizados são fictícios.
} 
Em um segundo momento, realizamos, também o acesso e a análise no AVA do Curso das oito disciplinas identificadas, tendo a permissão dos 5 professores, 9 tutores e 22 licenciandos, que participaram das referidas disciplinas, e ainda da coordenação do Curso. Nosso objetivo, nesse segundo momento, foi conhecer os conteúdos abordados.

A operacionalização da análise do AVA se realizou por meio de leituras das informações presentes no Ambiente Virtual das oito disciplinas. Cabe destacar que acessamos as informações registradas no AVA, pois ao iniciamos esta pesquisa, as disciplinas que nos interessavam já haviam sido oferecidas.

A partir das informações obtidas por meio da análise no AVA, identificamos que as disciplinas: (i) do Grupo A propuseram tarefas que envolveram o software GeoGebra, o LibreOffice, os Objetos de Aprendizagem e a WebQuest; (ii) do Grupo B propuseram tarefas que incluíram discussões sobre o conceito de tecnologias e sobre o uso das TDs na sala de aula, e tarefas que exigiram a gravação de videoaula; (iii) do Grupo C, dentre as tarefas propostas, haviam aquelas que demandavam o uso do software GeoGebra.

Tendo concluído ambos os momentos, iniciamos o processo de coleta de informações utilizando as técnicas do questionário e da entrevista.

A primeira técnica de coleta de dados utilizada foi o questionário (GIL, 1999). Nesta pesquisa, utilizamos dois questionários on-line: um, foi proposto aos 22 alunos matriculados no $8^{\circ}$ semestre do Curso, em 2016/2; e um outro, foi proposto aos 9 tutores do Curso. Identificar como as TDs foram abordadas nas disciplinas na perspectiva dos licenciandos e dos tutores foi o objetivo dos questionários. Obtivemos o retorno de 15 alunos e dos 9 tutores.

Os questionários foram gerados por meio dos Formulários Google ${ }^{12}$, uma ferramenta on-line com a qual é possível criar formulários e enviar o link de acesso por e-mail, permitindo que as pessoas os respondam virtualmente.

Utilizamos também o instrumento de coleta de dados entrevista (GIL, 1999). Realizamos uma entrevista com cada um dos professores que

\footnotetext{
12 https://www.google.com/intl/pt_br/forms/about/. Acesso em: 22 mar. 2018.
} 
ministraram as oito disciplinas identificadas. Assim, buscamos entender como os docentes organizaram o ensino das suas respectivas disciplinas. Convidamos os cinco professores que ministraram as disciplinas (vide Quadro 1), sendo que quatro deles concederam-nos a entrevista e um, o professor Lucas, não retornou nossos contatos.

Realizados ambos os procedimentos, finalizamos a etapa de pesquisa de campo e partimos em busca de um delineamento para as análises, realizado mediante leituras e releituras das informações coletadas, tendo em mente os objetivos e a questão de pesquisa. Identificamos, assim, quatro categorias emergentes $^{13}$ (FIORENTINI; LORENZATO, 2007), a saber: i) a dinâmica das disciplinas, aborda os instrumentos adotados pelos professores na organização do ensino das disciplinas; ii) o acompanhamento e a avaliação dos licenciandos, compreende os mecanismos propostos pelos docentes para o processo de assistência aos alunos e os procedimentos avaliativos; iii) $a$ participação dos licenciandos, aborda o modo que os professores e tutores perceberam o envolvimento dos licenciandos nas disciplinas; e iv) a abordagem das TDs e a implicação para a formação docente, evidencia o modo que os professores, licenciandos e tutores avaliam a abordagem das TDs pelas disciplinas, bem como seus efeitos para a formação do futuro professor.

Com essa sistematização, buscamos tratar o material coletado a fim de atender nossos objetivos e construir respostas à questão de investigação.

\section{A abordagem das Tecnologias Digitais no Curso de Licenciatura em Matemática PARFOR/EaD da UFU: alguns apontamentos}

Defendemos, em nossa pesquisa, fundamentados em Moura et al. (2016), que o professor, independentemente da modalidade educacional, é quem organiza o ensino: define ações, seleciona instrumentos, acompanha e avalia o processo de ensino e aprendizagem. Entendemos que as ações do professor na organização do ensino, apoiados nos mesmos autores, devem propiciar que

\footnotetext{
${ }^{13}$ Categorias emergentes, segundo Fiorentini e Lorenzato (2007, p.135), são categorias “obtidas, mediante um processo interpretativo, diretamente do material de campo". Os mesmos autores, também esclarecem que categorias são "classes ou conjuntos que contêm elementos ou características comuns" (p.134).
} 
a aprendizagem ocorra de forma sistemática, intencional e organizada, a fim de mobilizar e orientar os alunos frente ao objeto de estudo.

Posto isso, seguem as análises construídas no contexto da investigação. Salientamos que, em razão do limite de laudas para este artigo, será abordado em cada categoria alguns apontamentos principais. Para mais detalhamentos, sugerimos a consulta em Gonçalves (2018).

\section{A dinâmica das disciplinas}

Observamos que os principais recursos, citados pelos professores, utilizados no desenvolvimento das oito disciplinas para abordar as TDs foram: vídeos, os recursos do Moodle (fóruns e Glossários), e tarefas de leitura.

Com relação ao uso do vídeo no Curso, observamos o emprego dessa mídia pelos professores como: (i) videoaulas, produzidas pelos próprios docentes e empregadas para apresentar orientações acerca das disciplinas, ou seja, as atividades propostas, o cronograma, o conteúdo abordado; (ii) webconferências, utilizadas pelos professores como um meio de esclarecer dúvidas dos alunos; (iii) os vídeos tutoriais, empregados/produzidos pelos docentes para o uso do software GeoGebra; e (iv) os vídeos prontos, disponíveis na Internet acerca do funcionamento, especialmente, do software GeoGebra.

Com relação, a videoaula, além de ter sido um instrumento de ensino empregado pelos professores nas disciplinas, o recurso foi, também, objeto de estudo (SCHILLER; LAPA; CERNY, 2011) em algumas disciplinas, isto é, foi proposto aos licenciandos o planejamento e a gravação de uma videoaula.

A gente fez o que eu chamei de Regência Simulada. Peguei tópicos de Matemática do Ensino Médio e fiz um sorteio virtual. Então, eles [licenciandos] tiveram que fazer um plano de aula no Word, uma apresentação no PowerPoint e realizar a gravação de uma videoaula de 20 a 25 minutos, ministrando uma aula daquele tema e disponibilizar no Ambiente. (Profa. Daniela, entrevista, 15/12/2016). 
Entendemos que quando os licenciandos experienciam um processo desse tipo envolvendo as TDs, essa experiência pode mobilizá-los a uma possível familiaridade com tais ferramentas e uma atitude ativa, reflexiva sobre o conhecimento escolar e as novas tecnologias, vislumbrando, até mesmo, possibilidades de integração das TDs aos processos educacionais.

Estimular os licenciandos a refletir, a questionar quanto a confiabilidade e a fidedignidade das informações que podem ser acessadas pela Internet, foi uma preocupação também dos professores:

$\mathrm{Na}$ Internet tem muita coisa que você consegue acessar, só que é preciso que o professor saiba ser crítico, [...] nós tentamos desenvolver esse senso crítico nos alunos, fazer com que refletissem (Prof. Fernando, entrevista, 14/12/2016).

A esse respeito, Carneiro e Passos (2014) afirmam que o professor precisa ter muito cuidado ao utilizar conteúdo da Internet, uma análise prévia precisa ser realizada. Isso parece-nos fundamental de ser estimulado na Licenciatura, a fim de que os futuros professores assumam uma postura de análise ao selecionar TDs para o seu trabalho em sala de aula.

O fórum de discussão, um dos recursos do Moodle, foi outra ferramenta adotada pelos professores. O fórum é um "espaço destinado para um diálogo entre seus participantes sem a necessidade de estarem conectados no mesmo momento" (SILVA, 2015, p.81). Sobre o uso do fórum uma professora relata:

Uma dinâmica que a gente utilizou, para trabalhar com softwares, era que eles tinham que entrar em um site que a gente disponibilizou com vários softwares de Matemática, escolher um, conhecê-lo para depois relatar no fórum. (Profa. Daniela, entrevista, 15/12/2016).

Acreditamos que essa dinâmica de conhecer, explorar e relatar nos fóruns pode ter contribuído para que os licenciandos assumissem atitudes como investigar por si próprios, colaborar na realização de atividades profissionais, "aspectos sem dúvida importantes na caracterização da 
identidade do professor de matemática" (PONTE; OLIVEIRA; VARANDAS, 2003, p.188).

Ainda, a respeito do trabalho com softwares, podemos considerar que o GeoGebra ${ }^{14}$ foi o mais abordado. Com relação ao emprego desse software:

Eu fiz um pequeno tutorial em vídeo de como são as ferramentas do GeoGebra. Eu abria os menus, dizia o que estava usando, o que fazia e o que não fazia... fazia uma pequena apresentação do software junto com a construção de um exercício de lista. Na lista, tinham as construções que eles tinham que fazer. (Prof. Eduardo, entrevista, 10/01/2017).

Assim, observamos que, dentre as listas de exercícios propostas pelo professor Eduardo, havia exercícios que deveriam ser resolvidos utilizando-se o software GeoGebra. Para tanto, após o estudo teórico, foram propostos vídeos tutoriais, nos quais os professores apresentaram o software, suas potencialidades e limitações e, ainda, a resolução comentada de exercícios.

Acreditamos que essa dinâmica pode ter oferecido orientações aos licenciandos para a realização das atividades propostas e, ainda, permitindoos conhecerem e vivenciarem a utilização do software.

O Glossário foi, também, outro recurso/instrumento empregado pelos professores em suas disciplinas. A esse respeito, o professor Fernando relata:

Eles tiveram ainda que procurar coisas na internet e, a partir do que eles viram, criar um Glossário de forma colaborativa. Então, basicamente utilizamos o Glossário para trabalhar com Objetos de Aprendizagem, WebQuest, LibreOffice, softwares e para refletir sobre as tecnologias na Educação Matemática (Prof. Fernando, entrevista, 14/12/2016).

O Glossário é uma compilação, em ordem alfabética, de termos, com as respectivas definições, a respeito de uma determinada temática. O Glossário

\footnotetext{
${ }^{14}$ GeoGebra é um software livre de Matemática dinâmica que reúne conceitos de Geometria e Álgebra.
} 
foi proposto de duas formas: (i) os professores disponibilizavam termos, cada licenciando selecionava um, buscava sua definição e realizava a postagem no AVA; e, (ii) em conformidade com o tema estudado, cada licenciando escolhia um termo que lhe causava dúvida, buscava a definição e postava no Ambiente.

Entendemos que ao permitir acrescentar, visualizar e comentar termos inseridos, o Glossário possibilita o compartilhamento de ideias entre os alunos, tutores e professores, destaca a importância do registro escrito, da organização das ideias e da capacidade de síntese e reflexão.

Atividades que envolviam leitura e elaboração de sínteses escritas e suas postagens no AVA, também, foram propostas pelos professores:

Passei textos que falavam sobre as tecnologias na Educação Matemática que os alunos tinham que ler e escrever sínteses. (Prof. Fernando, entrevista, 14/12/2016).

Zabel e Malheiros (2015) sinalizam que o conhecimento teórico, oriundo da leitura de textos, é importante para o desenvolvimento profissional docente e para que o professor possa se sentir apto para o uso das TDs na sala de aula.

Nesse sentido, cremos que a abordagem teórica e prática precisam coexistir na formação docente. Todavia, entendemos que as leituras exercem um papel significativo nesse processo, instigando o docente a repensar, rever e ampliar sua visão sobre, no caso, algum recurso tecnológico digital; o que pode incidir na atuação educacional e enriquecer o exercício docente.

\section{O acompanhamento e a avaliação dos licenciandos}

As orientações naquelas disciplinas que abordaram as TDs no Curso, foram realizadas a partir: de uma agenda e de textos existentes no Guia impresso de cada disciplina; de videoaulas; e, por escrito nas páginas do AVA:

Todas as orientações das minhas disciplinas aconteceram via AVA, por meio de vídeos, por escrito no Ambiente e no Guia (Prof. Fernando, entrevista, 14/12/2016). 
As orientações na disciplina Introdução a $\mathrm{EaD}$ foram a partir de videoaulas, onde eu explicava o que aconteceria durante a disciplina. Nos Estágios, as orientações foram por escrito no AVA (Profa. Daniela, entrevista, 15/12/2016).

Outra ferramenta empregada para o acompanhamento dos licenciandos foram os fóruns de dúvidas, os quais, por sua vez, eram coordenados pelos tutores. Desse modo, introduzimos a figura do tutor no processo de acompanhamento dos licenciandos durante as disciplinas. Para Silva (2015), o tutor tem a missão de acompanhar e orientar os alunos no processo educativo, juntamente com os professores e sob sua orientação. A respeito dos tutores, os professores relatam:

Era minha tutora que estava mais próxima dos alunos, ela acompanhava tudo (Profa. Daniela, entrevista, 15/12/2016).

Qualquer coisa que os alunos não entendessem, eles tinham um tutor. [...]. A resposta do tutor era muito rápida (Prof. Fernando, entrevista, 14/12/2016).

Nesses trechos de entrevista, os professores destacam, em suas disciplinas, o papel dos tutores, os quais estiveram mais próximos dos licenciandos, oferecendo, com agilidade, respostas às suas demandas e, ainda, realizando a correção de atividades avaliativas. Dessa forma, avaliam Moore e Kearsley (2008, p.149), os tutores são "os olhos e os ouvidos do sistema".

Com relação aos procedimentos avaliativos adotados pelos professores em suas disciplinas, foram seguidas as recomendações citadas anteriormente, a saber: avaliações presenciais e o uso dos recursos via AVA:

Haviam muitas atividades via AVA, num total de 40 pontos: fóruns, resumo de textos e de vídeos, glossários... já no final do semestre tinha uma avaliação no valor de 60 pontos feita no polo. (Prof. Fernando, entrevista, 14/12/2016). 
Tínhamos as listas de exercícios via AVA, que valiam 40 pontos. E tínhamos a avaliação final escrita no valor de 60 pontos realizada no polo (Prof. Eduardo, entrevista, 10/01/2017).

As atividades a distância eram corrigidas pelos tutores a distância mediante chave de correção preparada previamente pelo docente. Silva (2015) lembra que o tutor presencial, por vezes, também, corrige trabalhos presenciais. Entretanto, pela análise das falas dos docentes, percebemos que as atividades presenciais avaliativas foram somente às avaliações finais, as quais foram corrigidas pelos professores. Sobre os critérios de correção:

[...] vejo que a formação não está na entrega de um arquivo, mas na participação dos alunos nas atividades, no seu mergulho nas tarefas propostas (Profa. Daniela, entrevista, 15/12/2016).

[...] eu ia acompanhando e já olhando, vendo o envolvimento, o andamento (Profa. Bruna, entrevista, 16/12/2016).

Entendemos que tais colocações, evidenciam indícios que vão ao encontro das afirmações de Resende (2004), para quem os procedimentos avaliativos na modalidade a distância devem ser planejados de maneira que se considere o processo em si e o seu resultado. Isto é, “deve levar em conta o processo em construção e não apenas o seu produto acabado, quando já não há possibilidade de interferências e da busca de alternativas àquela aprendizagem” (RESENDE, 2004, p.2-3).

Assim, acreditamos que há indícios que nos permitem inferir que os procedimentos de avaliação empregados pelos docentes prezaram não apenas pelo produto final, mas, também, pelo processo de realização das tarefas propostas, o envolvimento, a participação, o compartilhamento de ideias.

\section{A participação dos licenciandos}

A participação dos licenciandos nas disciplinas do Curso foi sinalizada pelos professores e tutores como limitada, em razão dos licenciandos 
dedicarem-se, apenas, a realização de atividades avaliativas e apresentarem dificuldades em trabalhar com às TDs. A respeito desse primeiro aspecto:

Eu esperava que os alunos participassem mais [...] Os alunos, geralmente, fazem o essencial [...] "O que é exigido? A tarefa tal e a tarefa tal. Certo, então eu vou cumprir somente essas tarefas”. A webconferência estava contando presença... foi uma coisa cobrada. Então, o aluno, como todo aluno, no presencial não é diferente, ele faz, mas só aquilo que é exigido (Profa. Daniela, entrevista, 15/12/2016).

Coadunando com esses apontamentos, o professor Fernando pontua:

Sobre a participação dos alunos, eu tentava picar os pontos nas atividades, um ponto aqui, um ponto ali... [...] tudo tinha que valer pontos, senão eles não faziam... inclusive, no presencial, também, é assim (Prof. Fernando, entrevista, 14/12/2016).

Entendemos, a partir dessas colocações, que os docentes externalizam certa crítica, desapontamento e, ao mesmo tempo, se veem aprisionados a uma situação em que a atribuição de uma nota aparece como uma condição diante das tarefas, ou seja, a "realização das atividades fica condicionada ao reforço positivo representado pela nota" (TAVARES; FONSECA, 2014, p.117). Embora haja indícios de que esses docentes valorizaram aspectos que não se resumissem apenas na distribuição de pontos, pareceu-nos que esse foi fator preponderante para a participação dos licenciandos nas tarefas propostas.

$\mathrm{O}$ segundo aspecto indicado, agora, pelos tutores como limitador da participação dos licenciandos nas disciplinas diz respeito as dificuldades de manuseio das TDs durante o Curso. Nesse sentido, relatam os tutores:

Percebi a dificuldade dos futuros professores para baixar os softwares, mesmo com as orientações, eles ficavam perdidos, quanto aos procedimentos de instalação e, posteriormente, a execução do mesmo [...] (Tutora Lara, questionário, 07/10/2016). 
Inicialmente, havia alunos que não conseguiam ligar o computador. No decorrer do tempo, conseguiram acessar a plataforma, e-mail, formatar textos e desenvolver atividade empregando softwares (Tutora Simone, questionário, 16/01/2017).

Desses registros das tutoras, percebemos que as dificuldades dos licenciandos com as TDs durante o Curso estavam relacionadas a questões técnicas e operacionais; e, mesmo com as orientações e acompanhamentos realizados, as tutoras notaram que os licenciandos ficavam confusos ao lidar com as tecnologias, de modo especial, pelo que parece, no início no Curso. Ao mesmo tempo, podemos inferir, a partir desses registros, que houve certa evolução na relação dos licenciandos com as TDs no decorrer do Curso, sobretudo, no que concerne a aquisição de conhecimentos técnicos.

Desse modo, embora acreditemos que, ao se empreender estudos na modalidade a distância, o indivíduo precise ter certa fluência no uso das TDs, entendemos que se evidencia a importância de se retomar e trabalhar, também, conhecimentos técnicos básicos pertinentes às TDs.

Parece-nos, assim, que um curso de formação de professores, cuja abordagem das TDs alie conhecimentos técnicos-didáticos-pedagógicos, pode permitir aos licenciandos, além de um possível uso das TDs como ferramentas de ensino em suas futuras aulas, uma melhor participação no curso, com menos limitações referentes ao manuseio de tais tecnologias.

\section{A abordagem das TDs e a implicação para a formação docente}

A formação de professores, afirma Kenski (2012), deve atender e responder às exigências atuais de utilização das TDs nos processos educacionais. Assim, parece-nos indispensável que os cursos de formação visem, também, formar professores preparados para a integração das TDs no ensino de Matemática (em nosso caso). Nesse sentido, os professores relatam:

[...] privilegiei o trabalho em sala de aula com uso das tecnologias, dar elementos aos alunos de modo que eles as conheçam e utilizem- 
nas em suas aulas quando forem professores (Prof. Fernando, entrevista, 14/12/2016).

[...] acredito que o aluno teve condições de ter a visão do trabalho docente com as tecnologias, o que pode influenciá-lo quando professor (Profa. Daniela, entrevista, 15/12/2016).

Notamos que os professores externalizam que buscaram, durante suas disciplinas, estabelecer relações entre as TDs trabalhadas e os conteúdos matemáticos. Acreditamos ser fundamental a criação desta conexão entre a sala de aula e as TDs. Afinal, como destacam Ponte, Oliveira e Varandas (2003, p.163), "parte importante do conhecimento profissional dos professores diz respeito ao uso das TIC [...]”. Os docentes, continuam os autores, precisam saber como utilizar os novos equipamentos e recursos digitais, bem como quais são o seu potencial, seus pontos fortes e seus pontos fracos.

Contudo, levando em conta essas colocações dos docentes, ao analisarmos os registros dos tutores e licenciandos, observamos dissonâncias:

Entendo que o curso apresenta as TD, mas não ofereceu momentos para que eles [licenciandos] realmente explorassem e pensassem em atividades para as aulas na Educação Básica. [...] (Tutora Lara, questionário, 07/10/2016).

A meu ver, faltou o desenvolvimento de atividades voltadas para a Educação Básica. Atividades em que os alunos pudessem pensar em maneiras de trabalhar com as TD na Educação Básica (Tutora Simone, questionário, 16/01/2017).

Corroborando essas afirmações, apontam os licenciandos:

Penso que poderia haver um conteúdo específico, talvez uma disciplina mais específica, que aborda as TD para ser trabalhada na sala de aula (Licenciando Diego, questionário, 07/11/2016).

Poderia ter aulas específicas sobre os conteúdos da Educação Básica desenvolvidos com as TD. Seria excelente trazer para a sala de aula 
o que está sendo trabalhado no curso com as TD (Licenciando Vitor, questionário, 29/09/2016).

Podemos observar que embora os professores tenham afirmado que buscaram promover a aproximação entre as TDs e a sala de aula, os registros dos licenciandos e dos tutores parecem-nos revelar que os próprios objetivos das disciplinas e busca dos docentes não foram totalmente alcançados ou não compreendidos pelos docentes e/ou pelos tutores e alunos. Nesse sentido, outros licenciandos, também, escrevem:

A minha dificuldade é aprender a encaixar os conteúdos matemáticos nos programas estudados (Licencianda Amanda, questionário, 20/10/2016).

Percebo que o curso trabalhou mais o manusear das TD e a teoria, não tanto o como trabalhar na sala de aula (Licenciando Diego, questionário, 07/11/2016).

Acreditamos que esses registros reforçam os apontamentos dos tutores de que os licenciandos não conseguiram criar links entre as atividades propostas pelas disciplinas e a sala de aula. Isso pode, ainda, evidenciar que a abordagem realizada das tecnologias pelos professores somente apresentou as TDs e, talvez, não tenha instigado os licenciandos a pensarem em possibilidades de uso das TDs para/na sala de aula e/ou não os tenha mobilizado a perceberem tais tecnologias como ferramentas de ensino.

Para Kenski (2012), é preciso que os cursos de formação permitam aos docentes se sentirem confortáveis para utilizar os recursos digitais. Estar confortável, para a autora, significa "conhecê-los, dominar os principais procedimentos técnicos para sua utilização, avaliá-los criticamente e criar novas possibilidades pedagógicas, partindo da integração desses meios com o processo de ensino" (p.77).

Em uma avaliação mais geral em relação a abordagem das TDs pelas disciplinas porém, professores, alunos e tutores partilham do entendimento 
de que é necessário a continuidade dos estudos despertados no Curso para que os futuros professores venham a utilizar tais tecnologias em sala de aula:

A gente aqui dá a base, mas as possibilidades que ele [futuro professor] tem com essas tecnologias todas são quase infinitas. Ele tem que estar sempre buscando algo a mais para sua formação (Prof. Eduardo, entrevista, 10/01/2017).

Os conhecimentos sobre as TD apresentadas no curso foi uma base para um futuro aprofundamento. [...] (Licencianda Larissa, questionário, 09/12/2016).

[...] O curso inicia o caminho, agora, cabe ao aluno prolongá-lo com autonomia para utilizar às TD em sua futura prática (Tutora Simone, questionário, 16/01/2017).

Embora concordemos na necessidade da formação constante frente as TDs, entendemos, a partir do exposto, na necessidade de se repensar aspectos relacionados a abordagem das tecnologias realizada pelas disciplinas para a sala de aula de Matemática. Afinal, serão os egressos desses cursos que possivelmente estarão em sala de aula, lidando com os nossos jovens que vivem cada vez mais mergulhados no mundo digital.

\section{Algumas Considerações}

Esta pesquisa foi orientada pela seguinte questão de investigação: como as Tecnologias Digitais são metodologicamente abordadas pelos professores no Curso de Licenciatura em Matemática, na modalidade a distância, da Universidade Federal de Uberlândia?

Nesse sentido, verificamos que no referido Curso haviam 8 disciplinas, dentre as 40 disciplinas da sua grade curricular, que abordaram as TDs. Tal situação, levou-nos a refletir a respeito da abordagem das TDs não estar centrada em determinadas disciplinas, sendo relevante que estejam presentes, de modo articulado, em todas as disciplinas, permitindo a construção de conhecimentos acerca das TDs durante todo o Curso. 
Constatamos que as TDs, metodologicamente ${ }^{15}$, foram abordadas pelos professores nessas oito disciplinas por meio: da busca em sites na Internet de softwares para o uso no ensino de Matemática, seguido, de debates em fóruns de discussão; da construção de Glossários com termos relacionados a Objetos de Aprendizagem, WebQuest e softwares; da resolução de exercícios com o software GeoGebra; de fóruns de discussão sobre o conceito de tecnologias; da elaboração de sínteses de artigos científicos que tratam do uso das TDs na sala de aula; da construção de um plano de aula e da gravação de uma videoaula ministrando uma aula de um conteúdo matemático.

Nessa organização do ensino das disciplinas, verificamos que os professores manifestaram a busca em abordar as TDs de modo que os licenciandos conhecessem-nas e refletissem criticamente, analisando e vislumbrando possibilidades de sua integração no ensino da Matemática.

Os licenciandos sinalizaram para a aquisição de conhecimentos técnicos no decorrer das disciplinas para com a lida das máquinas, porém, indicam que não conseguiram criar conexões entre as atividades propostas e a sala de aula e que não se sentem preparados para o uso das TDs no contexto escolar. Tais aspectos foram, igualmente, assinalados pelos tutores.

Nesse sentido, olhando para ações de formação dos professores formadores no que diz respeito a abordagem das TDs, há indicativos evidenciando que, em grande parte, o desenvolvido, na verdade, somente apresentou, apontou, ressaltou a importância de se utilizar um software, tendo poucos momentos nas quais as TDs foram utilizadas/exploradas no Curso como instrumentos de ensinar e de aprender.

Em face do exposto, parece-nos, então, que as disciplinas identificadas que abordaram as TDs, possibilitaram aos licenciandos, como constatado em pesquisa de Zabel e Malheiros (2015, p.127), "tanto a produção de conhecimentos tecnológicos, que envolve, por exemplo, o desenvolvimento de habilidades para operar determinadas tecnologias digitais, quanto a produção

\footnotetext{
${ }^{15} \mathrm{O}$ fato do professor formador escolher um instrumento/recurso/procedimento para trabalhar uma determinada TD, entendemos já ser um indício de metodologia.
} 
de conhecimento tecnológico pedagógico [...]"; em nosso caso, relativo ao saber da existência de recursos tecnológicos, já referente ao como eles podem ser utilizados no ensino de Matemática, há dissonâncias no que relatam os professores e no que escrevem os licenciandos e tutores.

Desse modo, considerando-se que os tutores estiveram próximos dos licenciandos e esses sendo os indivíduos impactados pela abordagem formativa proposta, este estudo levanta indícios, então, de que houve a necessidade de um maior direcionamento e cuidado pelos professores na abordagem e no estabelecimento de conexões entre as TDs e o contexto escolar, para que os futuros professores desenvolvessem conhecimentos a respeito da sua integração, enquanto ferramentas de ensino, aos processos de ensino e aprendizagem de Matemática.

Desejamos que este estudo ofereça contributos à área de Educação Matemática e estimule reflexões e o repensar da abordagem formativa das TDs para a sala de aula nos cursos de licenciatura Matemática a distância e, do mesmo modo, nos presenciais, como uma possibilidade para que essas cheguem e tornem-se de fato parte integrante da sala de aula de Matemática.

\section{Referências}

BRASIL. Ministério da Educação. Plano Nacional de Formação dos Professores da Educação Básica. Brasília: MEC, 2009.

CANTINI, M. C. et al. O desafio do professor frente as novas tecnologias. In: CONGRESSO NACIONAL DE EDUCAÇÃO, 6., 2006, Curitiba. Anais... Curitiba: PUC/PR, 2006. p.875-883.

CARNEIRO, R. F.; PASSOS, C. L. B. A utilização das Tecnologias da Informação e Comunicação nas aulas de Matemática: limites e possibilidades. Revista Eletrônica de Educação, São Carlos, v.8, n.2, p.101-119, 2014.

CHASSOT, A. Alfabetização científica: uma possibilidade para a inclusão social. Revista Brasileira de Educação, s/v, n.22, p.89-100, 2003.

FARIA, A. A.; SALVADORI, A. A Educação a Distância e seu movimento histórico no Brasil. Revista das Faculdades Santa Cruz, Curitiba, v.8, n.1, p.15-22, 2010.

FIORENTINI, D; LORENZATO, S. Investigação em educação matemática: percursos teóricos e metodológicos. 2. ed. Campinas: Autores Associados, 2007. 
FREITAS, M. T. M. Formação de professores de Matemática: cuidados essenciais nas relações de aprendizagem em contexto EaD. Acta Científica, Patos de Minas, v.6, n.6, p.245-255, 2014.

GONÇALVES, E. H. A utilização de tecnologias digitais no curso de Licenciatura em Matemática PARFOR/EaD da Universidade Federal de Uberlândia. 2018. 205f. Dissertação (Mestrado em Educação) - Universidade Federal de Uberlândia, Uberlândia, 2018.

GIL, A. C. Métodos e técnicas de pesquisa social. 5. ed. São Paulo: Atlas, 1999.

KENSKI, V. Tecnologias e Ensino Presencial e a Distância. Campinas: Papirus, 2012.

LOPES, R. P. Formação para uso das Tecnologias Digitais de Informação e Comunicação nas licenciaturas das Universidades Estaduais Paulistas. 2010. 226 f. Dissertação (Mestrado em Educação) - Universidade Estadual Paulista Júlio de Mesquita Filho, Presidente Prudente, 2010.

MINAYO, M. C. S. O desafio da pesquisa social. In: DESLANDES, S. F.; GOMES, R.; MINAYO, M. C. S. (Org.). Pesquisa Social. 29. ed. Petrópolis: Vozes, 2010. p.9-29.

MOORE, M.; KEARSLEY, G. Educação a Distância. São Paulo: Cengage, 2008.

MOURA, M. O. et al. A atividade orientadora de ensino com unidade entre ensino e aprendizagem. In: MOURA, M. O. (Org.). A atividade pedagógica na teoria históricocultural. 2. ed. Campinas: Autores Associados, 2016. p.93-125.

NEVES, C. M. C. A educação a distância e a formação de professores. In: ALMEIDA, M. E. B.; MORAN, J. M. (Orgs.). Integração das Tecnologias na Educação. Brasília: SEED/MEC, 2005. p.211-221.

PONTE, J. P.; OLIVEIRA, H.; VARANDAS, J. M. O contributo das tecnologias de informação e comunicação para o desenvolvimento do conhecimento e da identidade profissional. In: FIORENTINI, D. (Org.). Formação de professores de matemática. Campinas: Mercado de Letras, 2003. p.159-192.

RESENDE, R. L. S. M. Avaliação processual e formativa na Educação à Distância. In: CONGRESSO INTERNACIONAL DE EDUCAÇÃO A DISTÂNCIA, 11., 2004, Salvador. Anais... Salvador: ABED, 2004. p.1-10.

ROSINI, A. M. As Novas Tecnologias da Informação e a Educação a Distância. 2. ed. São Paulo: Cengage, 2014.

SCHILLER, J.; LAPA, A. B.; CERNY, R. Z. Ensinar com as tecnologias de informação e comunicação: retratos da docência. E-curriculum, São Paulo, v.7, n.1, p.1-19, 2011.

SILVA, S. F. Licenciatura em Matemática na modalidade a distância do Instituto Federal do Triângulo Mineiro. 2015. 143 f. Dissertação (Mestrado em Tecnologias, Educação e Comunicação) - Universidade Federal de Uberlândia, Uberlândia, 2015. 
TAVARES, N. S.; FONSECA, D. G. Avaliação nas aulas de educação física em escolas de Viamão/RS. Revista Didática Sistêmica, Rio Grande, v.16 n.1, p.113-127, 2014.

ZABEL, M.; ALMEIDA, H. R. F. L. Um retrato da formação online do professor de Matemática. In: BORBA, M. C.; ALMEIDA, H. R. F. L. (Orgs.). As Licenciaturas em Matemática da Universidade Aberta do Brasil (UAB): uma visão a partir da utilização das Tecnologias Digitais. São Paulo: Livraria de Física, 2015. p.29-47.

ZABEL, M.; MALHEIROS, A. P. S. A formação inicial do professor na modalidade a distância para o uso das tecnologias digitais no ensino de matemática: o caso de uma disciplina de prática de ensino. Alexandria, Florianópolis, v.8, n.3, p.113-130, 2015.

Recebido em julho de 2018.

Aprovado em maio de 2019. 